EDITORIAL

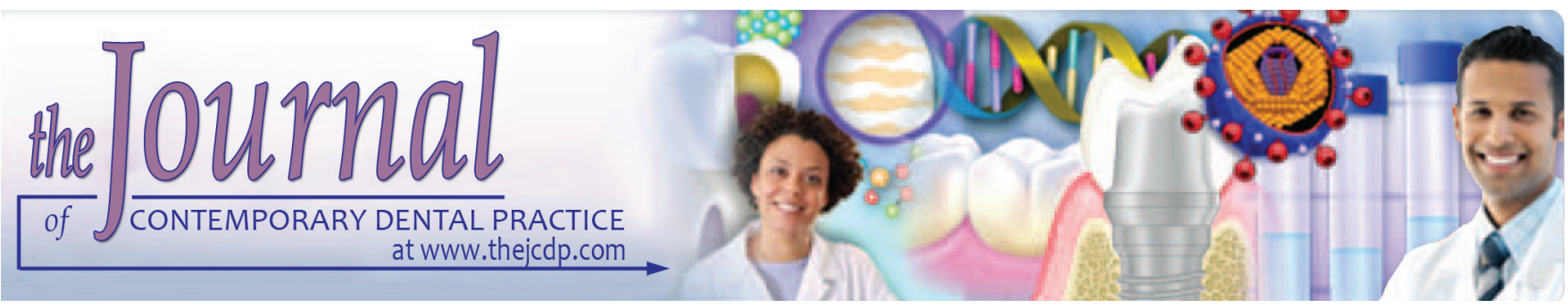

\title{
Effects of the Residues from the Endodontic Sealers on the Longevity of Esthetic Restorations
}

${ }^{1}$ Matheus C Bandeca, ${ }^{2}$ Milton C Kuga, ${ }^{3}$ Ana CS Diniz, ${ }^{4}$ Keren CF Jordão-Basso, ${ }^{5}$ Mateus R Tonetto

How to cite this article: Bandeca MC, Kuga MC, Diniz ACS, Jordão-Basso KCF, Tonetto MR. Effects of the Residues from the Endodontic Sealers on the Longevity of Esthetic Restorations. J Contemp Dent Pract 2016;17(8):615-617.

Source of support: Nil

Conflict of interest: None

\section{INTRODUCTION}

The substances used in the root canal treatment, especially sodium hypochlorite solution and oxidant agents, can negatively interfere on the bond strength of the adhesive systems to dentin and on the dental crowns fracture resistance ${ }^{1,2}$ In order to minimize these effects, the application of antioxidants, such as sodium ascorbate and alphatocopherol has been proposed. ${ }^{3,4}$ Other procedures carried out after the endodontic treatment can also influence the adhesion, as the type of the method and substances are employed in the removal of the residues from endodontic sealer in the pulp chamber immediately after the root canal obturation. ${ }^{5}$ However, the knowledge and the consequences from this interaction are still poorly understood.

Chemical methods are the principal way for the pulp chamber cleaning, and the use of ethanol or isopropyl

\footnotetext{
${ }^{1,2,5}$ Professor, ${ }^{3,4}$ Student

${ }^{1,3}$ Department of Postgraduate Program in Dentistry, CEUMA University, São Luis, Maranhão, Brazil

${ }^{2}$ Department of Restorative Dentistry, School of Dentistry, Univ Estadual Paulista, Araraquara, São Paulo, Brazil

${ }^{4,5}$ Department of Postgraduate Program in Integrated Dental Science, University of Cuiabá, Mato Grosso, Brazil
}

Corresponding Author: Matheus C Bandeca, Professor Department of Postgraduate Program in Dentistry, CEUMA University, São Luís, Maranhão, Brazil, e-mail: mbandeca@ gmail.com alcohol is routinely employed. ${ }^{6}$ In contrast, the persistence of residues on the dentin is directly related to the chemical composition of the root canal sealer and the type of solution used for its removal..$^{6-8}$ Eucalyptol, 95\% ethanol, $70 \%$ isopropylalcohol, and $70 \%$ ethanol are unable to completely remove the resinous-based sealer residues from the dentin surface. ${ }^{6}$ Moreover, $95 \%$ ethanol is inefficient to completely remove the epoxy-based (AH Plus), methacrylate-based (Epiphany SE), and salicylate-based (Sealapex) sealers residues of dentin. ${ }^{9}$ These residues present its setting time after a determined period and can be a physical barrier to the formation of the hybrid layer in the dentin-adhesive system interface. ${ }^{10-12}$ So, what is the importance of these residues on the adhesion of the adhesive systems to pulp chamber dentin?

The formation of a suitable hybrid layer in dentin is fundamental for the longevity of the direct esthetic restorations. ${ }^{13,14}$ One suggestion is to use the adhesive system prior to the root canal obturation, although this condition presents the persistence of residues from endodontic sealer on the adhesive system. ${ }^{8}$ But, these residues may be possibly removed when the acid etching is immediately performed after the dentin cleaning. ${ }^{15}$ The doubt is about the exact time for the adhesive system application, because if it is immediately applied and the esthetic restoration is delayed, the adhesion will be damaged once a new cleaning procedure and/or chemical substances from the temporary restoration may negatively interfere on the bond strength of the composite materials. ${ }^{16}$ But if the acid etching is delayed, it is possible that the residues from the endodontic sealer will not be properly removed, compromising the formation of the hybrid layer due to its physical interposition between the dentin and the adhesive system.

This is critical point because many clinicians perform only the endodontic treatment and then the patient is referred to another professional. New intermediate restorative materials, such as bulk-fill resin can be a solution 

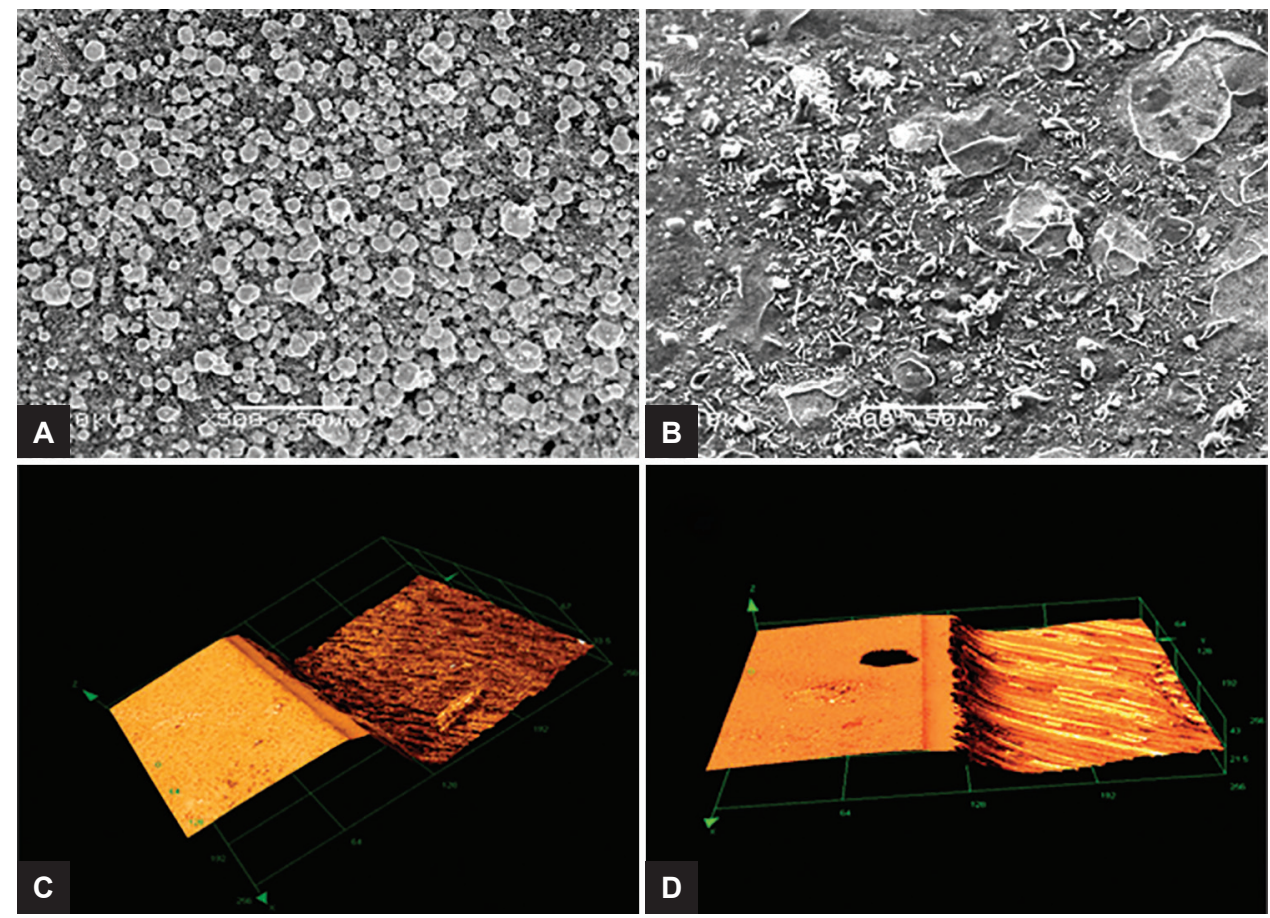

Figs 1A to D: (A) The presence of residues of endodontic sealer on the dentin; $(B)$ on the dentin bonding after cleaning protocols; $(C)$ the absence of the hybrid layer; and $(D)$ the presence of hybrid layer in dentin interface/adhesive system

since it presents easy application and also prevents the cusp fracture of the endodontically treated teeth with mesial-occlusal-distal (MOD) cavity. ${ }^{17}$ Therefore, in order to remove these residues in the pulp chamber after endodontic treatment, it is interesting to adapt the dentin etching method, i.e., the use of the self-etching adhesive system immediately after the dentin cleaning protocols and if it is possible the esthetic restoration confection or at least the pulp chamber filling using the bulk-fill composite. However, further studies should be conducted to evaluate the effects of these factors on the adhesion of the adhesive systems to dentin in order to develop a dentin cleaning protocol after the endodontic obturation. (Figs $1 \mathrm{~A}$ to D).

\section{REFERENCES}

1. Furuse AY,Cunha LF, BarattoSP, LeonardiDP,Haragushiku GA, Gonzaga CC. Bond strength of fiber-reinforced posts to deproteinized root canal dentin. J Contemp Dent Pract 2014 Sep;15(5):581-586.

2. Leonardo R de T, Kuga MC, Guiotti FA, Andolfatto C, FariaJúnior NB, Campos EA, Keine KC, Dantas AA. Fracture resistance of teeth submitted to several internal bleaching protocols. J Contemp Dent Pract 2014 Mar;15(2):186-189.

3. Bontorim FC, Kuga MC, Cioffi SP, Só MVR, Faria G, Pereira JR. Effect of two formulations of $10 \%$ sodium ascorbate on fracture resistance of endodontically treated tooth submitted to dental bleaching with hydrogen peroxide associated titanium dioxide nanoparticles. J Res Dent 2014;2(1):14-20.

4. Sasaki RT, Flório FM, Basting RT. Effect of $10 \%$ sodium ascorbate and $10 \% \alpha$-tocopherol in different formulations on the shear bond strength of enamel and dentin submitted to a home use bleaching treatment. Oper Dent 2009;34(6): 746-752.

5. Roberts S, Kim JR, Gu LS, Kim YK, Mitchell QM, Pashley DH, Tay FR. The efficacy of different sealer removal protocols on bonding of self-etching adhesives to AH Plus-contaminated dentin. J Endod 2009 Apr;35(4):563-567.

6. Kuga MC, Só MV, De Faria-Júnior NB, Keine KC, Faria G, Fabricio S, Matsumoto MA. Persistence of resinous cement residues in dentin treated with different chemical removal protocols. Microsc Res Tech 2012 Jul;75(7):982-985.

7. Kuga MC, Só MV, De Campos EA, Faria G, Keine KC, Dantas AA, Faria NB Jr. Persistence of endodontic methacrylate-based cement residues on dentin adhesive surface treated with different chemical removal protocols. Microsc Res Tech 2012 Oct;75(10):1432-1436.

8. Kuga MC, Faria G, Rossi MA, do Carmo Monteiro JC, BonettiFilho I, Berbert FL, Keine KC, Só MV. Persistence of epoxybased sealer residues in dentin treated with different chemical removal protocols. Scanning 2013 Jan-Feb;35(1):17-21.

9. Victorino KR, de Campos EA, Só MVR, Kuga MC, FariaJunior NB, Keine KC, Alvarenga FAZ. Ethanol is inefficient to remove endodontic sealer residues of dentinal surface. RSBO 2013;10(3):211-216.

10. Chávez-Andrade GM, Kuga MC, Duarte MAH, Leonardo R de T, Keine KC, Anna-Junior AS, Só MVR. Evaluation of the physicochemical properties and push-out bond strength of MTA-based root canal cement. J Contemp Dent Pract 2013 Nov;14(6):1094-1099.

11. Magro MG, Kuga MC, Victorino KR, Vázquez-Garcia FA, Aranda-Garcia AJ, Faria-Junior NB, Faria G, Luis Shinohara A. Evaluation of the interaction between sodium hypochlorite and several formulations containing chlorhexidine and its effect on the radicular dentin-SEM and push-out bond strength analysis. Microsc Res Tech 2014 Jan;77(1):17-22. 
12. Magro MG, Kuga MC, Aranda-Garcia AJ, Victorino KR, Chávez-Andrade GM, Faria G, Keine KC, Só MV. Effectiveness of several solutions to prevent the formation of precipitate due to the interaction between sodium hypochlorite and chlorhexidine and its effect on bond strength of an epoxy-based sealer. Int Endod J 2015 May;48(5):478-483.

13. Pashley DH. Dentin bonding: Overview of the substrate with respect to adhesive material. J Esthet Dent 1991 Mar-Apr;3(2): 46-50.

14. Perdigão J, May KN Jr, Wilder AD Jr, Lopes M. The effect of depth of dentin demineralization on bond strengths and morphology of the hybrid layer. Oper Dent 2000 May-Jun;25(3): 186-194.
15. Aranda-Garcia AJ, Kuga MC, Vitorino KR, ChávezAndrade GM, Duarte MA, Bonetti-Filho I, Faria G, Só MV. Effect of the root canal final rinse protocols on the debris and smear layer removal and on the push-out strength of an epoxy-based sealer. Microsc Res Tech 2013 May;76(5):533-537.

16. Gomes MF, Botta SB, Matos AB, Netto NG. The interference of the cleaning procedure of root walls with two different solvents on the adhesion of fiberglass intraradicular posts. J Contemp Dent Pract 2012 May;13(3):275-279.

17. Yasa B, Arslan H, Yasa E, Akcay M, Hatirli H. Effect of novel restorative materials and retention slots on fracture resistance of endodontically-treated teeth. Acta Odontol Scand 2015;18:1-7. 